\title{
Extra-Adrenal Retroperitoneal Paraganglioma
}

National Cancer Institute

\section{Source}

National Cancer Institute. Extra-Adrenal Retroperitoneal Paraganglioma. NCI Thesaurus.

Code C5328.

A benign or malignant sympathetic parag ang lioma arising from the retroperitoneum, outside the adrenal gland. 